\title{
Americanistas, diplomáticos y líderes de la emigración españoles en el México del Centenario: la «embajada intelectual» como modelo de acción panhispanista (1909-1910)*
}

\author{
Spanish Americanists, Diplomats and Emigrant Leaders \\ in the Mexico of Centenario: the «Intellectual Embassy» \\ as a Model of Pan-Hispanist Action (1909-1910)
}

\author{
Gustavo H. Prado \\ orcid.org/0000-0002-8909-5258 \\ Universidad Complutense de Madrid
}

Durante los centenarios de las independencias, importantes intelectuales españoles desplegaron una enérgica acción panhispanista en Hispanoamérica. Se analizará aquí cómo americanistas, diplomáticos y líderes de la emigración españoles se coaligaron en las postrimerías del porfiriato para publicitar este programa, estudiando el viaje de Rafael Altamira a México a través del modelo conceptual de embajada intelectual.

Palabras ClaVE: Panhispanismo; México; Embajada Intelectual, Americanistas, Diplomáticos, Líderes de la Emigración, Rafael Altamira.

During the period of Centennial Celebrations of Latin American Independence, Spanish intellectuals of great reputation organized a persistent panhispanist campaign in Hispanic America. This paper analyzes the way in which americanists, diplomats and Spanish emigration leaders made common caused with, to promote their ideas, during the previous years to Porfiriato in Mexico. The concept of intellectual embassy will be used here to analyze their strategies.

KeYwords: Panhispanism, Mexico, Intellectual Embassy, Americanists, Diplomats, Emigrant Leaders, Rafael Altamira.

Copyright: (C) 2016 CSIC. Este es un artículo de acceso abierto distribuido bajo los términos de una licencia de uso y distribución Creative Commons Attribution (CC-by) España 3.0.

* El presente artículo se encuadra dentro del proyecto «Intelectuales, letrados y embajadores culturales: su relación con la migración española en Argentina, Cuba, México y Uruguay, 1840-1936» (MEC, HAR2012-36806/HIST). Contenidos parciales de este artículo han sido presentados a discusión en el Simposio Internacional América: poder, conflicto y política, Universitat de Barcelona, 12 a 14 de septiembre de 2011; y en el Congreso Internacional: Flujos migratorios entre dos mundos: EuropaAmérica Latina (s. XIX-XXI), Universidad Complutense de Madrid, 11 a 12 de marzo de 2013. 


\section{El movimiento americanista español y la promoción del panhispanismo}

Como es sabido, los centenarios de las independencias abrieron una interesante revisión de las relaciones entre España y América Latina e importantes debates acerca del tipo de vínculos culturales, económicos o políticos que debían desarrollarse de allí en adelante. En aquellos años el principal impulso español para replantear estas relaciones no provino del gobierno de la Restauración, sino de la sociedad civil y, más concretamente, del movimiento americanista español.

Este movimiento recogía amplias corrientes de opinión, sensibilidades e intereses, que movilizaban a individuos y grupos ligados con el redescubrimiento de una América en fase acelerada de crecimiento, que lograba atraer a emigrantes españoles tras utopías de ascenso social. Los sectores más concienciados del americanismo español impulsaron, en la última década del siglo XIX, un proceso organizativo ${ }^{1}$ del que surgieron nuevos espacios americanistas. Esto permitió al americanismo constituir un pequeño pero dinámico lobby panhispanista ${ }^{2}$ que, trascendiendo los intereses sectoriales, planteaba la necesidad de potenciar y jerarquizar las relaciones culturales, políticas y económicas con las repúblicas americanas, para resituar a España en el concierto internacional, dentro de un bloque hispano de naciones.

Este grupo de presión institucionalizado, que pretendió erigirse en cerebro y portavoz del americanismo español, puede caracterizarse como un colectivo de notables, miembros de las élites de una sociedad desigual, en proceso de modernización económica y gobernada por un sistema político fraudulento y excluyente, propio del capitalismo oligárquico.

Luego del Desastre de 1898, la irrupción pública de este movimiento ${ }^{3}$ logró atraer nuevos elencos de notables del mundo intelectual, político y económico, permitiendo la emergencia de nuevos referentes doctrinarios, atentos a asociar sus reivindicaciones con otras que circulaban en el campo cultural y el campo de poder. Esta repolitización del america-

1 Cagiao Vila y Rey Tristán, 2006.

2 Nos apartamos aquí de las consideraciones del panhispanismo como ideología impregnada de «nostalgia neoimperial» (Aken, 1980 [1959]. Marcilhacy, 2010, 35-32) y también de la propuesta de considerar al panhispanismo como una lectura conservadora e inicial del americanismo, diferenciada ideológicamente del hispanoamericanismo progresista (Sepúlveda, 2005, 99-121).

3 Altamira, 1898. García-Montón, 1999. 
nismo - asociada con la crítica regeneracionista y la emergencia del nacionalismo español— ${ }^{4}$ permitió superar el horizonte mental del autonomismo cubano, la era de las exhortaciones fraternales y de la diplomacia de gestos.

Entre $1892^{5}$ y 1910 , desde estos sectores organizados del movimiento americanista se ensayarían dos estrategias: la primera procuraba atraer e integrar subordinadamente a las élites americanas en iniciativas españolas tuteladas o financiadas por el Estado; la segunda proponía una intervención autónoma desde la sociedad civil en el terreno americano, para prohijar vínculos con las élites locales - en especial con los emergentes sectores hispanófilos - de modo de crear una comunidad de intereses que pudiera comprometer, más tarde, a los gobiernos respectivos con un programa panhispanista.

Esta segunda estrategia partía de dos supuestos: el primero, que los gobiernos españoles no podían liderar este acercamiento en sus etapas iniciales, debido a la incapacidad o resistencia de las burocracias ministeriales; el segundo, que era peligroso dejar abandonada la acción americanista a las iniciativas de particulares, ya que de la simple sumatoria de intervenciones de emprendedores culturales carentes de respaldos institucionales, de unidad orgánica y de una doctrina rectora, jamás se podría generar una política panhispanista coherente.

Así pues, el fracaso de la cooptación de intelectuales americanos, sumado al desinterés de los gobiernos por innovar en estas materias y a la creciente profusión de aventuras individuales, contribuyó a que se perfilara una estrategia de intervención - que es posible conceptualizar bajo el tipo ideal de embajada intelectual — basada en la iniciativa unilateral y autárquica de instituciones americanistas. Esta estrategia apostaba, pues, por una vía de acción paradiplomática que, más allá de una agenda ligada a los intereses específicos de quienes la patrocinaban, desplegara otra agenda paralela, cuya prioridad era la propaganda panhispanista.

Si bien este tipo de intervención no se encarnaba en un perfil único, quienes protagonizarían esta etapa incierta de aproximación serían intelectuales de orientación liberal-reformista. Este protagonismo no solo puede explicarse por la composición socio-profesional del lobby americanista, sino también porque la viabilidad del giro panhispanista se jugaba, en

4 Niño, 1993. Sepúlveda Muñoz, 2005.

5 Bernabéu Albert, 1987. 
América, en los terrenos culturales, en la opinión pública y en los imaginarios históricos, donde la hispanofobia seguía entorpeciendo acercamientos más profundos. ${ }^{6}$

Las intervenciones de los embajadores intelectuales del movimiento americanista, junto con la acción espontánea de los emprendedores culturales, serían decisivas en esta etapa inicial de la reconstrucción de las relaciones. Tanto unos como otros poseían el respaldo de su prestigio intelectual o profesional, sumado a las contribuciones eventuales que recabaran de sus redes sociales; pero solo los embajadores intelectuales del movimiento americanista podían contar con el respaldo de instituciones que les concedieron su representación oficial y se hicieron cargo de las gestiones que les permitirían obtener el plácet de las universidades, academias, asociaciones profesionales y foros de la sociedad civil donde se formaban las élites latinoamericanas con las que se pretendía establecer una alianza política e intelectual.

Uno de los mejores ejemplos de embajada intelectual española en la América de los centenarios fue el protagonizado por Rafael Altamira, quizás el principal de los nuevos referentes del americanismo español surgidos en la coyuntura de fin de siglo. Este significado republicano y regeneracionista, discípulo de Joaquín Costa y Francisco Giner de los Ríos, emprendería entre 1909 y 1910 , un viaje americanista como delegado de la Universidad de Oviedo — donde comenzó a dictar cátedra de Historia del Derecho en 1898-, con los objetivos manifiestos de: tomar contacto con las instituciones educativas y del área cultural de Argentina, Uruguay, Chile, Perú, México y Cuba; establecer acuerdos de intercambio regular de recursos humanos y bibliográficos con las universidades latinoamericanas; y promover la creación de academias correspondientes a la Real Academia de Ciencias Morales y Políticas, la cual lo había nombrado, también su representante oficial. ${ }^{7}$

Junto a estos aspectos propositivos, Altamira desplegó una intensa actividad pedagógica en instituciones universitarias, académicas, museísticas, culturales y de la sociedad civil, ejemplificando prácticamente las potencialidades del intercambio intelectual. Altamira fue escrupuloso a la hora de disertar sobre materias de su competencia, las cuales eran objeto de especial interés para un Estado en construcción: la institucionalización

6 Rama, 1982, 67-159.

7 Altamira, 1911. Melón Fernández, 1987. Prado, 2008b. 
universitaria de la historia; la pedagogía de la historia en los niveles primarios y secundarios de la enseñanza; la pedagogía popular como instrumento de integración social; el Derecho consuetudinario y la Historia del Derecho.

Junto a estas cuestiones, la agenda paralela de Altamira se centró en la difusión de los avances científicos españoles; en refutar las leyendas negras sobre la cultura española; en proponer la fundación de institutos de investigación latinoamericanos en Sevilla para explotar el Archivo de Indias; y en publicitar los contenidos económicos y políticos del programa panhispanista, haciendo énfasis en la necesidad de una asociación igualitaria de los países hispanos.

Este periplo y el regreso de Altamira a España dieron lugar a demostraciones multitudinarias — con una notable repercusión mediática y política- en Montevideo, Lima, Mérida, México, Coruña, Santander, Alicante y Oviedo. Si bien existieron algunas disonancias notorias en $\mathrm{Cuba}^{8}$ y surgieron post facto detractores ideológicos de la labor de Altamira en Asturias, ${ }^{9}$ lo cierto es que el incontrovertible éxito del profesor ovetense entre las élites y las opiniones públicas latinoamericanas había significado un impulso formidable para el americanismo español.

Este resultado fue posible, en buena medida, por la eficaz logística del rector de la Universidad de Oviedo, Fermín Canella, y también por el apoyo de los españoles en América, tanto de los diplomáticos de la Restauración como, sobre todo, de los líderes de la emigración.

Existiendo investigaciones recientes acerca de esta embajada intelectual, particularmente de su experiencia en Argentina,${ }^{10}$ nos detendremos aquí en su escala mexicana - comprendida entre el 12 y el 20 de diciembre de 1909 y el 12 de enero y el 12 de febrero de 1910-, recurriendo a la abundante documentación inédita conservada en los diferentes repositorios que recogen el archivo original de Altamira y en archivos estatales que recogen informes diplomáticos, cruzando esta evidencia con documentación de prensa. El objetivo no es solo contribuir a recuperar la memoria de un acontecimiento significativo para la compleja historia de las relaciones hispano-mexicanas; ${ }^{11}$ sino también proveer elementos para construir el modelo de embajada intelectual, como un instrumento capaz de dar

8 Valero Juan, 2003.

9 Melón, 1987. Prado, 2008a, 223-246.

10 Pelosi, 2005. Prado, 2008b.

11 Suárez Cortina, 2013. 
cuenta del proceso de acercamiento entre España e Hispanoamérica en este período. ${ }^{12}$

\section{Altamira en México}

La llegada de Altamira a México estuvo precedida por las noticias del espectacular impacto que había tenido su misión en Sudamérica. Estos antecedentes sirvieron de incentivo para que los sectores afines a la empresa retroalimentaran el clima de apoteosis hispanista, en un contexto propicio para la revisión positiva de la herencia cultural española. ${ }^{13}$

Sin abandonarnos a una simple descripción erudita - que realizamos con anterioridad ${ }^{14}$ y seguimos aquí, en parte- es necesario brindar un panorama sintético de las actividades de Altamira en México. Altamira pronunció un ciclo de cuatro conferencias para la Escuela Nacional de Jurisprudencia, presentado por el secretario de Instrucción pública y Cultura, Justo Sierra, y clausurado por el director de la Escuela y presidente de la Academia de Ciencias Sociales, Pablo Macedo, ante la presencia del embajador español y del presidente Porfirio Díaz. ${ }^{15}$

Altamira disertó también en la Escuela Nacional Preparatoria, en la Escuela de Artes y Oficios, en la Escuela Normal de Maestros, en el Museo Nacional de Arqueología, Historia y Etnología, en el Colegio Militar, en el Casino Español para el Nacional Colegio de Abogados, en el Ateneo de la Juventud, y en el Salón de Actos de la Escuela Nacional de Artes y Oficios, para la Academia Nacional de Ingenieros y Arquitectos. ${ }^{16}$

Durante su estancia Altamira fue invitado a visitar la Sociedad Mexicana de Geografía y Estadística, la Biblioteca Nacional, las excava-

12 Este tipo ideal deberá identificar los factores estructurales y coyunturales que favorecieron el acercamiento hispano-mexicano, los actores y los hechos, explorando sus relaciones, para construir a partir de todo esto - y del conocimiento que tenemos sobre las experiencias de Altamira en el Río de la Plata - un modelo explicativo que, como tal, abstraiga los aspectos más significativos de la realidad, para componer una herramienta teórica capaz de aplicarse a los fenómenos constituidos en objetos del estudio histórico y contrastarse con la evidencia disponible de esta y otras escalas del viaje de Altamira y, más allá, con la evidencia de otras experiencias americanas de viajeros intelectuales españoles.

13 Pérez Vejo, 2011.

14 Prado, 2008b, 37-41.

15 Archivo Histórico de la Universidad de Oviedo, Fondo Rafael Altamira, en catalogación (AHUO/FRA, en cat), Caja VI. Para el pormenor de este ciclo y títulos de las conferencias, véase Prado, 2008b, 37. La edición crítica de tres de las conferencias por Jaime del Arenal Fenochio, en Altamira, 1993.

16 Para una relación y temáticas de estas conferencias, véase Prado, 2008b, 38. 
ciones de Teotihuacan, el Liceo Mexicano, la Casa de Correos, el Colegio de la Marina. ${ }^{17}$ También fueron visitadas la escuela de niñas indígenas de Xochiman, la Escuela Superior de Xochimilco y la Escuela Ignacio M. Altamirano. ${ }^{18}$

En el plano político, Altamira fue arropado por el jefe de Estado y varios de sus secretarios, por el obispo, las autoridades de Mérida y el gobernador de Yucatán. ${ }^{19}$ La Secretaría de Instrucción solicitó un dictamen a Altamira a propósito del proyecto de fundación de la Universidad Nacional de México, designándolo como futuro profesor titular de una cátedra de Historia del Derecho. ${ }^{20}$

Estas actividades, sus relaciones y la propia dinámica del viaje, hicieron que Altamira fuera exaltado por la prensa ${ }^{21}$ y acumulara distinciones entre las que podemos destacar las membresías honorarias de la Academia Central Mexicana de Jurisprudencia y Legislación ${ }^{22}$ y de la Sociedad Científica Antonio Alzate, ${ }^{23}$ y la corresponsalía de la Sociedad Mexicana de Geografía y Estadística. ${ }^{24}$

Altamira fue agasajado también con numerosos banquetes por altos funcionarios, por sus colegas universitarios, por profesores de nivel secundario y primario, por el Colegio de Abogados, por las legaciones española y argentina, por el Liceo y por la Liga de Acción Social de Mérida. ${ }^{25}$

En su informe oficial, Altamira destacó el acontecimiento social que significó su partida de la capital mexicana rumbo a Yucatán. ${ }^{26}$ En esta

17 Ibidem, 38-39.

18 «Fiesta en honor de Altamirano», La escuela mexicana, vol. VI, n. ${ }^{3} 33$, México, 30 de enero de 1910, 520-534. Véase Prado, 2008b, 39.

19 El gobernador yucateco durante el viaje americanista, Muñoz Arístegui, le solicitó a la remisión de las leyes obreras españolas y comentarle la repercusión positiva de su paso por Mérida. Carta de Enrique Martín Muñoz Arístegui a Rafael Altamira, Mérida de Yucatán, 25 de febrero de 1910, Instituto de Enseñanza Secundaria Jorge Juan de Alicante, Legado Altamira (IESJJA/LA), C-4/185.

20 Altamira, 1911, 350. Prado, 2008b, 40. de 1910 .

21 «Entusiasta recepción al Dr. Altamira», Diario Yucateco, Mérida de Yucatán, 7 de febrero

22 Asín Vergara et al., 1987, 115. El acto se celebró el 29 de enero de 1910, y en la sesión oficial hicieron uso de la palabra los académicos Rodolfo Reyes y Roberto A. Esteva Ruiz. Véase Prado, 2008b, 39.

23 Carta de R. Aguilar y Santillán, Sociedad Científica Antonio Alzate a Rafael Altamira, México, 25 de enero de 1910, IESJJA/LA, C-4/63.

24 Carta de la Sociedad Mexicana de Geografía y Estadística a Rafael Altamira, México, 14 de enero de1910, IESJJA/LA, C-4/31.

25 Carta de Gonzalo Cámara y Tomás Castellano Acevedo, Liga de Acción Social de Mérida, a Rafael Altamira, Mérida de Yucatán, 11 de febrero de 1910, IESJJA/LA, C-4/105.

26 Altamira, 1911, 352. 
ocasión, la Escuela Nacional Preparatoria convocó «a lo más selecto de la cultura de México» y lanzó una campaña de publicidad callejera para atraer multitudes a una impactante demostración en su honor que se desarrolló en la estación ferroviaria y que logró emocionar a Altamira:

Siento que ahora veis en España una hermana dispuesta a ir con vosotros sea como fuere. ¡Benditos seáis vosotros, porque habéis hecho que mi palabra fructificara e hiciera de dos pueblos una sola alma! ${ }^{27}$

A raíz de esta anécdota y del corolario que de ella extrajo Altamira, es necesario recordar que su éxito en México y en los demás países visitados no puede ser explicado teniendo en cuenta solo el carisma de su protagonista o los contenidos de su discurso, ignorando los diferentes contextos de recepción americanos de los emprendimientos culturales o embajadas intelectuales españoles. Estos contextos no pueden ser reducidos a un patrón único, debiéndose observar, en cada país, las razones subyacentes de que una iniciativa con tales trasfondos políticos, obtuviera este tipo de respuesta. Es innegable que existió un cierto clima de época y preocupaciones compartidas en torno al imperialismo anglosajón y las doctrinas social-darwinistas de las relaciones internacionales, ${ }^{28}$ pero ello no es óbice para reconocer que la recepción positiva del panhispanismo obedeció a diferentes razones, por ejemplo, en el Río de la Plata que en México.

\section{El apoyo decisivo de los españoles de América a la misión de Altamira}

Más allá de la existencia de condiciones estructurales que tendían a acercar a España e Hispanoamérica —relacionadas con unos sistemas políticos homólogos y complementariedades socio-demográficas- y de un clima cultural favorable para la recepción del discurso panhispanista, es inevitable constatar que estas situaciones y tendencias fueron manipuladas y potenciadas, en la coyuntura de los centenarios, por ciertos individuos y grupos que, reunidos en torno a intereses concretos, apostaron por asociarse al emprendimiento americanista de la Universidad de Oviedo.

27 «El último día de estancia en México del Señor Altamira. Cariñosa despedida en la estación», El Imparcial, México, 3 de febrero de 1910.

28 Marcilhacy, 2010, 114-209. 
El prestigio de Altamira como historiador y jurista, el respaldo institucional que le brindaban la Universidad de Oviedo y la Academia de Ciencias Morales y Políticas, o los sesudos contenidos del programa panhispanista y los proyectos ovetenses, con ser necesarios no eran suficientes para suscitar la repercusión deseada. En efecto, ignoto para el gran público, huérfano del respaldo de partidos políticos y desprovisto de una representación gubernamental, Altamira necesitaba del concurso activo de individuos confiables que, gracias a su inscripción en redes sociales cosmopolitas - de las que participaban españoles de uno y otro lado del Atlántico y miembros de las clases dominantes hispanoamericanas-, pudieran abrirle camino entre los altos funcionarios, caciques políticos o dirigentes sociales que tenían capacidad para negociar acuerdos bilaterales en torno de las propuestas panhispanistas.

Si el profesor ovetense pudo acceder a los despachos de seis jefes de Estado, si pudo obtener el respaldo público de secretarios y ministros, si pudo disfrutar de una vasta y profunda cobertura periodística para todas sus actividades, todo ello fue, en gran medida, porque los principales líderes de la emigración ${ }^{29} \mathrm{y}$, en algunos casos, los diplomáticos españoles movilizaron sus influencias en el entramado de la sociedad de acogida, en la cual la comunidad española se hallaba inserta y procuraba integrarse en unas condiciones más aventajadas. Explotando su capacidad para operar como bisagras entre los mundos intelectuales, políticos y sociales de España e Hispanoamérica, estos agentes acicatearon a las colonias de emigrantes - siempre necesitadas de recrear el lazo identitario con la patria lejanapara que no desaprovecharan esta oportunidad de demostrar a España la supervivencia de su patriotismo y jerarquizar, en su tierra de residencia, los cuestionados valores de la hispanidad.

Durante su viaje de 1909-1910 Altamira obtuvo, en mayor o menor medida, los respaldos de los líderes étnicos y diplomáticos españoles, siendo en las etapas donde mejor y más equilibradamente se articularon, aquellas que destacaron por ser especialmente fructíferas: Argentina, Uruguay y la que más nos interesa aquí, México.

No es de extrañar que este proyecto necesitara sumar apoyos en la sociedad civil asturiana, cántabra y gallega, teniendo en cuenta que esta empresa fue planificada como una iniciativa universitaria autárquica y sustraída, voluntariamente, del tentador concurso de los políticos. ${ }^{30}$ Pero el

29 Núñez Seixas, 2003.

30 Altamira, 1911, 18-34. 
éxito de la misión de Altamira se jugaba, sobre todo, en América misma y estaba en relación con la capacidad de asegurarse el apoyo moral y el soporte material de las comunidades de emigrantes.

Con estos apoyos, sumados a los aportes de universidades, academias o gobiernos latinoamericanos, se pretendía evitar la dependencia económica de las estructuras ministeriales españolas o la subordinación de este proyecto patriótico a los intereses de los partidos dinásticos. De allí que no se esperara apoyo alguno de unos diplomáticos españoles prevenidos y hostiles hacia los republicanos que solían visitar sus jurisdicciones sin ahorrar críticas al sistema político español.

Sin embargo, Altamira, como opositor pragmático de la Restauración y asumiendo un papel esencialmente institucional, no despreció, allí donde hubo de ofrecérsele, la cobertura oficial u oficiosa de los encargados de negocios o del personal consular. ${ }^{31}$

En Buenos Aires, con la titularidad de la legación española vacante, se contó con la activa colaboración del vicecónsul José María Sempere y sus allegados, personalmente vinculados con Altamira y la Universidad de Oviedo $; 2$ pero en las etapas siguientes, a medida de que se despejaban dudas y recelos, el papel jugado por las legaciones fue cada vez mayor. Pese a carecer de instrucciones específicas, los ministros plenipotenciarios Germán de Ory, en Uruguay, Silvio Fernández Vallín, en Chile, Julio del Arroyo, en Perú, y Pablo Soler, en Cuba, jugaron un papel importante a la hora de vincular a Altamira con los altos cargos políticos con los que era menester dialogar. Este giro se debió, sin duda, a que los diplomáticos se percataron pronto de que esta embajada intelectual estaba desbordando su natural ámbito académico, pudiendo ser capitalizada por España para mejorar las relaciones con los países americanos. ${ }^{33}$

Consciente de la necesidad de contar con el apoyo de los españoles de América, pero también del riesgo que comportaba caer preso de sus agendas e intereses inmediatos, Altamira procuró mantener ciertas distancias para no quedar secuestrado por los diplomáticos, ni atrapado en las rencillas facciosas de los emigrantes. El recurso al que apeló para ello fue reforzar el carácter patriótico y neutral de su empresa, lo cual resultó aceptable tanto para

31 Altamira, 1911, 53-81, 287-296, 341-358, 401-413 y 487-490.

32 Prado, 2008b, 24.

33 Despacho n. ${ }^{\circ}$ 127, Montevideo, 10 de octubre de 1909, Archivo del Ministerio de Asuntos Exteriores, España (AMAE), Correspondencia Uruguay 1901-1909, H-1796. Despacho n. ${ }^{\circ} 164$, Santiago de Chile, 8 de noviembre de 1909, AMAE, Correspondencia Chile, H-1441. 
unos como para otros, conscientes de que los réditos colaterales que pudieran obtenerse del éxito de Altamira solo podrían capitalizarse para beneficio de España y de sus emigrantes si los españoles en América mantenían una unidad de discurso y acción de cara a las élites políticas latinoamericanas.

En líneas generales, los diplomáticos y las dirigencias comunitarias guardaron las espaldas del catedrático, que se había convertido en un polo de atracción para muchos de sus compatriotas, en tanto que protagonista de un fenómeno colectivo de identificación, que hizo que muchos españoles vieran encarnados en Altamira aquellos aspectos de la lejana España que movilizaba sus nostalgias, anhelos y esperanzas. Pero estaba claro que, en medio de este clima de exaltación hispanista, entre tanta lisonja, tanto banquete, tanto personaje rondándolo, no eran pocos los pícaros que intentaban sacar partido de aquel acontecimiento ${ }^{34}$ o beneficiarse indirectamente de él. ${ }^{35}$ En efecto, la cercanía de Altamira, su accesibilidad y su influencia coyuntural en las autoridades atrajeron demandas de varios individuos para que los ayudara a conseguir trabajo, ascensos y aumentos de sueldo, contratos, homologaciones de títulos universitarios o, en el caso de los más altruistas, para obtener beneficios económicos para la colectividad. ${ }^{36}$

En todo caso, la repercusión pública de la labor de Altamira en México debió mucho a la decidida acción de la pequeña comunidad española ${ }^{37}$ la cual se movilizó activamente para asegurar el feliz desarrollo de la empresa ${ }^{38}$ asociándose para ello con el gobierno mexicano, que puso a disposición del viajero los recursos necesarios para su desplazamiento y manutención dentro del país. ${ }^{39}$

34 El presidente del Centro Castellano de México, el leonés A. Larín, solicitó a Altamira autorización para registrar y usar su nombre, retrato y unos «pensamientos apropiados para el caso» para lanzar una lujosa edición de chocolates dedicada a «los estudiantes de México» (Carta de los socios de la Gran Fábrica de Chocolates y Dulces a Rafael Altamira, México 2 de febrero de1910, IESJJA/LA, C-4/87).

35 Altamira citaba en un reportaje, la ilustrativa frase de un comerciante español de Buenos Aires que declaraba vender mejor sus aceites después del éxito de sus cursos y conferencias. Véase: «Entusiasta recepción al Doctor Altamira», Diario Yucateco, Mérida de Yucatán, 7 de febrero de 1910.

36 Ignacio Arcos Pérez se valió de su nombre y del clima españolista que dejó su viaje en Uruguay para obtener una oportuna cancelación de deudas para el Hospital Español de Montevideo. Carta de Ignacio Arcos Pérez a Rafael Altamira, Montevideo 4 de diciembre de 1909, IESJJA/LA, C-3/160.

37 Prado, 2005, 29-53 y 461-491. Ledezma, 2011 y 2013.

38 Carta de Francisco (Paco) [?] a Rafael Altamira, Metepec, 6 de junio de 1909, IESJJA/LA, C-2/59.

39 Despacho n. ${ }^{\circ} 4014$ de la mesa 2. a de Sección de Educación Secundaria, Preparatoria y Profesional dependiente de la Secretaría de Estado y del Despacho de Instrucción Pública y Bellas Artes de México, México, 4 de enero de 1910, IESJJA/LA, C-4/22. 
El poderoso industrial José Sánchez Ramos no dudó en ofrecer el Casino Español de la ciudad de México, que entonces presidía, para que Altamira presentara el programa americanista de la Universidad de Oviedo ante Porfirio Díaz y su gabinete, ${ }^{40}$ y el Centro Asturiano le abrió sus salones para que disertara acerca de «La misión docente de las asociaciones españolas de América». ${ }^{41}$ En Veracruz, Altamira fue invitado a conferenciar por el Casino Español de esa ciudad, y en Mérida de Yucatán la colectividad le encargó tres conferencias para público general y una lección pedagógica especial para los maestros primarios. ${ }^{42}$

Pero, pese a que la comunidad española pareció estar unida en torno a Altamira, lo cierto es que proliferaban en ella diversos conflictos fundados en la convivencia de diferentes exilios e inmigraciones, en las tensiones políticas peninsulares y mexicanas, y también en la mezquina e implacable competencia por poderes y dignidades intracomunitarios.

Custodio Llanos, uno de los propietarios de la compañía El Abastecimiento Eléctrico de México, alertaba al profesor español de que se encontraba frente a una comunidad desgarrada por la herencia del caciquismo y del faccionalismo político peninsular, pero también por el egoísmo y vanidad de muchos notables. Llanos, entusiasmado con el proyecto de Altamira de abrir una escuela de inmigrantes en México, no tenía duda de que «todo el elemento sano de la colonia» lo apoyaría sin reservas. Para este empresario, una colectividad española — que unida «tiene un gran poder»— podía sacar muchos beneficios de esta institución. De allí que debieran extremarse las precauciones y desoír las «opiniones bastardas» alejadas de la «obra común» y patriótica, que solo servirían de coartada para profundizar una desunión que perjudicaría a todos. ${ }^{43}$ En otra carta, Llanos reafirmaba sus consejos de que Altamira utilizara su prestigio intelectual, su talento persuasivo, sus «espléndidas relaciones personales» $\mathrm{y}$, sobre todo, su condición de no residente — «que le escuda contra críticas y censuras»- para interpelar a los emigrantes «desde un lugar de absoluta neutralidad» política, puesto que «ninguna de las personalidades de nuestra Colonia por más desinterés, acendrado patriotismo y esfuerzo personal

40 Altamira, 1911, 346. Prado, 2008b, 173.

41 Discurso pronunciado por Rafael Altamira en el Centro Asturiano, México, 8 de marzo de 1910, AHUO/FRA, en cat., Caja s/n.

42 «Entusiasta recepción al doctor Altamira», Diario Yucateco, Mérida de Yucatán, 7 de febrero de 1910. Véase Prado, 2008b, 173-174. C- $4 / 30$.

43 Carta de Custodio Llanos a Rafael Altamira, México, 12 de enero de 1910, IESJJA/LA, 
que pusiera en tamaña obra lograría un resultado final favorable a sus propósitos». ${ }^{44}$ El llanisco Alfredo Romano también escribió a Altamira rogándole su intervención para favorecer la unidad de la comunidad española fragmentada regionalmente y dividida en facciones irreconciliables..$^{45}$

Pese a su prescindencia, Altamira debió posicionarse junto a las autoridades de las asociaciones españolas, alejándose discretamente de los elementos conflictivos que pudieran entorpecer sus actividades y su prédica de confraternización hispano-mexicana. Claro que este pragmatismo tuvo sus costes; por ejemplo, en el informe final del ministro plenipotenciario español se registra la «aislada disonancia» del diario católico El País, el cual se habría puesto «desde el primer instante en guardia por si el Sr. Altamira desenvolvía determinados criterios, aquí imperantes y exclusivos en la enseñanza oficial». ${ }^{46}$

\section{Bernardo de Cólogan y Telesforo García}

Si bien los inminentes fastos de los centenarios de las revoluciones americanas, instalaron en las colonias emigrantes un clima entre prevenido y festivo, propenso al agasajo de los visitantes de su lejana patria, las dimensiones y el fervor que cobró el acompañamiento de la embajada cultural de Altamira excedió todo lo previsible, no porque ese tipo de repercusión popular fuera desconocida, sino porque esta movilización se produciría para ensalzar a un sabio ignoto para las multitudes.

En este sentido, creemos que este fenómeno debe imputarse principalmente a la enérgica acción promocional que desplegaron algunos diplomáticos españoles y, sobre todo, líderes emergidos de las élites empresariales, profesionales o intelectuales de la colectividad ${ }^{47}$ —muchos de los cuales emigraron o se exiliaron en América tras la caída de la Primera República-, identificados con los objetivos y fundamentos del americanismo español o leales a sus relaciones personales previas con Canella o Altamira. C-4/32.

44 Carta de Custodio Llanos a Rafael Altamira, México, 14 de enero de 1910, IESJJA/LA, C-4/73.

45 Carta de Alfredo Romano a Rafael Altamira, México, 29 de enero de 1910, IESJJA/LA,

46 Despacho n. 8 del ministro plenipotenciario de S.M. al ministro de Estado, La misión en México del Sr. Altamira, catedrático de la Universidad de Oviedo, México, 12 de febrero de 1910, AMAE, Política México 1905-1912, H-2557. Para las críticas de El País y el debate que abrió en México, véase: Ledezma, 2011, 111-118.

47 Lida, 1994. Cerutti, 1995. 
Así pues, en México las apuestas convergentes de dos españoles, uno de ellos un notorio diplomático y el otro un influyente líder comunitario, resultaron decisivas para publicitar la embajada intelectual de Altamira cuyo éxito parecía, por diversas razones, convenir a todos.

El primero de ellos, Bernardo de Cólogan y Cólogan (1847-1921), ${ }^{48}$ ministro plenipotenciario en México, flanqueó al viajero durante toda su estancia y no tuvo reparos para elogiarlo en sus informes confidenciales al ministro de Estado. ${ }^{49}$ Cólogan ponderó la labor de Altamira en la promoción de España en el exterior y recomendó al gobierno proveer a que esta pauta de moderación, neutralidad, patriotismo e idoneidad intelectual se repitiera en quienes realizaran futuras incursiones en México, advirtiendo la necesidad de prevenir que acudieran «imitadores... más bien sueltos, sin condiciones para la obra apostólica», que podrían causar daños a «estos ideales y fecundas corrientes de aproximación»..0

Cólogan creía que la instintiva hispanofobia podría ser sorteada siempre y cuando se hiciera una buena gestión del mensaje hispanista, que explotara la existencia de un background cultural común y las demandas de los propios mexicanos, cuestiones que explicarían, en definitiva, el triunfo de Altamira:

aun cuando indudablemente han ido y continuarán desvaneciéndose disentimientos o resquemores tradicionales, estos pueblos guardan y guardarán siempre una gran susceptibilidad respecto a nosotros; pero también pienso que cuando el mérito sólido y verdadero de un español, o éxito de España, se ofrece a ellos espontáneo, fraternal, desinteresado e ingenuo, despierta lozano el sentimiento de raza, ya que el amor a lo indígena no ha de ocultarles que no están en ello la civilización y promesas del porvenir, propendiendo entonces hacia nosotros, no por altruismos nacionales en que no creo, sino porque en su afinidad y convivencia con una España culta vigorizada, presentirían el fortalecimiento de su propio ser y patria. Así me explico los entusiasmos que he presenciado, yo que en esto me he precavido siempre contra ilusiones, y los Vivas a España provocados por un Altamira, notables ya en las efusiones del banquete en el Casino Español, pero más sonoros, y también de más precio por no mediar

48 Cólogan había sido compañero en su juventud de Fermín Canella en el Seminario Real de Vergara. Véase: Carta de Fermín Canella a Rafael Altamira, Oviedo, 16 de noviembre de 1910, Archivo de la Fundación Residencia de Estudiantes de Madrid, Fondo Altamira (AFREM/FA), RAL 2. Sobre la labor de Cólogan en México, véase Mac Gregor, 1992 y 2000.

49 Despacho n. ${ }^{\circ} 8$ del ministro plenipotenciario de S.M. al ministro de Estado. La misión en México del Sr. Altamira, catedrático de la Universidad de Oviedo, México, 12 de febrero de 1910, AMAE, Política México 1905-1912, H-2557.

50 Idem. Mac Gregor, 1992, 13-14. 
tributo o sugestión de cortesía, en la Estación del ferrocarril durante casi media hora de larga despedida. ${ }^{51}$

Altamira reconoció la labor de Cólogan ${ }^{52}$ y, ya en España, no dudó en actuar como su intermediario ante sus políticos liberales afines, publicitando un proyecto de 1908 del embajador sobre un nuevo marco tarifario postal que incentivaría la producción y circulación de libros españoles. Cólogan pidió a Altamira que influyera en Madrid para que su proyecto tuviera curso favorable en la administración española, donde sufría constantes derivaciones administrativas, ${ }^{53}$ y que hablara en su favor al presidente José Canalejas e incluso, si deseaba, «picando más alto», en obvia alusión a Alfonso XIII. ${ }^{54}$

El segundo de los apoyos de Altamira fue el cántabro Telesforo García (1844-1918), ${ }^{55}$ empresario periodístico y minero — con inversiones diversificadas en el comercio, las finanzas y los ferrocarriles- y líder comunitario, cuya base de poder estaba no solo en sus periódicos, sino en el Casino Español, donde se congregaban los emigrantes más ricos e influyentes.

García fue el verdadero factótum del éxito de Altamira en México, arropándolo personalmente —llegó a alojarlo en su casa— - y desempeñándose como intermediario permanente entre el viajero, el gobierno, la sociedad civil mexicana, las instituciones culturales y la comunidad española. ${ }^{56}$

García fue el negociador español que acordó lo esencial de la agenda de Altamira en el país con su amigo personal, el secretario de Instrucción Pública de México, Justo Sierra, tal como se desprende de sus informes al

51 Despacho n. ${ }^{\circ} 8$ del ministro plenipotenciario de S.M. al ministro de Estado. La misión en México del Sr. Altamira, catedrático de la Universidad de Oviedo, México, 12 de febrero de 1910, AMAE, Política México 1905-1912, H-2557.

52 Altamira, 1911, 357

53 Carta de Bernardo de Cólogan a Rafael Altamira, México, 24 de junio de 1910, IESJJA/LA, C-6/37.

54 Carta de Bernardo de Cólogan a Rafael Altamira, México, 3 de julio de 1910, IESJJA/LA, C-6/57. Para los argumentos de Cólogan, véase Prado, 2008b, 347-348, nota 98.

55 Telesforo García había visitado la Universidad de Oviedo en junio de 1905, cuando Canella era vicerrector, pronunciando una conferencia acerca de la «Educación del emigrante» y siendo agasajado por la Junta directiva de la Extensión Universitaria, fundada por inspiración de Rafael Altamira. Más tarde y como retribución a su apoyo a Altamira, García sería nombrado profesor honorario de la Extensión Universitaria. Sobre García, véase Domínguez y Cerutti, 2006. Ledezma, 2012.

56 Carta de Roberto A. Esteva Ruiz a Telesforo García, México, 13 de enero de 1910, IESJJA/LA, C-22/100. Carta de Telesforo García a Rafael Altamira, México, 29 de abril de 1909, IESJJA/LA, C-2/43. Carta de Telesforo García a Rafael Altamira, México, 11 de febrero de 1910, IESJJA/LA, C-4/107. 
catedrático ovetense en fechas previas a su arribo. Si bien Sierra había conocido a Altamira y a Canella en 1900, cuando era juez del Tribunal Supremo y asistió al Congreso Hispano-Americano de Madrid, este rápido acceso a su despacho estuvo garantizado por la activa intermediación de García. ${ }^{57}$

García y Sierra habían formado parte del grupo de jóvenes liberales y positivistas que colaboraran en El Precursor (1874-1876), que editaron el periódico «político, científico y literario» La Libertad (1878-1884) y, luego, el periódico Orden y Progreso. Con Porfirio Díaz en el poder, García, Sierra y otros científicos fueron moderando, sin perderlas, sus aspiraciones liberal-reformistas, valorando progresivamente la estabilidad e integrándose, críticamente, a los círculos del poder.

Claro que la relación privilegiada que entabló Altamira con García provocó tensiones con otros referentes de la emigración. José Porrúa, el librero, editor y entonces director del periódico El Correo Español, enemigo de García, se quejó ante el rector Canella de la desconsideración de Altamira al no visitarlo en su redacción y acusándolo veladamente de parcialidad. Altamira, rápidamente informado del asunto,$^{58}$ explicó a Porrúa su decisión de no visitar ningún periódico para evitar desaires con aquellos a los que no pudiera asistir. ${ }^{59}$ Pero esta réplica y la oferta de publicar sus conferencias con su sello editorial ${ }^{60}$ no evitó que Porrúa reafirmara enfáticamente su visión negativa de la dirigencia comunitaria que se habría aprovechado de su desconocimiento del país, rodeándolo en todos los pasos y

57 «Primero. El Ministerio ayudará a Vd. con los gastos de viajes en México y tal vez algo para los del camino. Segundo. El Gobierno pagará algunas conferencias y procurará que Estados como Jalisco, San Luis, Puebla, Veracruz y Yucatán, paguen dos o tres cada uno. Tercero. Yo procuraré que nuestro Casino Español pague por lo menos otras dos conferencias. Cuatro. Si yo estoy aquí para cuando Vd. llegue, tiene la obligación de aceptar el hospedaje en mi casa o en la de Don Iñigo Noriega, otro compatriota de lo más significado en esta Capital, quién me ha pedido que le imponga a Vd. esta obligación en el caso aludido. Reduciendo el asunto a números, no me parecería exagerado que Vd. obtuviese un resultado libre de veinticinco a treinta mil pesetas en una temporada de dos meses. Ciertamente que debería ser bastante más como premio a su ciencia y a su labor. Pero ya sabe Vd. que solo cantantes y toreros tienen el privilegio de hacerse pagar grandes sumas por habilidades discutibles. La ciencia no alcanza todavía tan alto predicamento» (Carta de Telesforo García a Rafael Altamira, México, 29 de abril de 1909, IESJJA/LA, C-2/43).

58 Cartas de Fermín Canella a Rafael Altamira, Oviedo, 10 de enero de 1910 y 23 de febrero de 1910, AFREM/FA, RAL 2.

59 Borrador de carta de Rafael Altamira a José Porrúa, s/l y s/f (escrita a posteriori del 10 de enero de 1910 y antes del 5 de febrero de 1910), IESJJA/LA, C-22/8. Borrador de nota de Rafael Altamira a José Porrúa, s/l y s/f, IESJJA/LA, C-22/7. Carta de Fermín Canella a Rafael Altamira, Oviedo, 23 de febrero de 1910, AFREM/FA, RAL 2.

60 Carta de José Porrúa a Rafael Altamira, México, 22 de enero de 1910, IESJJA/LA, C-4/51. 
sumergiéndolo en un «ambiente falso» que nada tenía que ver con la realidad de la colectividad ni con las relaciones de esta con la sociedad mexicana. De allí que Altamira, «por no darse cuenta de estas cosas», fuera también responsable de haber «perjudicado» o cuando menos de no haber servido eficazmente «a la misma causa que aquí lo ha traído y a los verdaderos intereses de la Colonia y de la Patria». ${ }^{61}$

Pese a los costes que pudiera tener, parece claro que honrar la asociación privilegiada con García fue una prioridad para Altamira y que ello hizo que su relación se prolongara epistolarmente, ya concluido el viaje. ${ }^{62}$ En su correspondencia puede verse cómo Altamira confió abiertamente a García sus inquietudes respecto de la suerte del americanismo español, recibiendo algunos consejos acerca de las precauciones que debía tener con el presidente asturiano de la Unión Ibero-Americana de Madrid, Faustino Rodríguez de San Pedro. ${ }^{63}$

Esta mutua confianza se debió en parte al prudente comportamiento de Altamira y a la aprobación entusiasta que supo suscitar su labor en la opinión pública mexicana, la cual revertía positivamente en una comunidad española esperanzada en tener un representante informal, pero consecuente, ante el siempre distante gobierno español.

Estas expectativas llevaron a Telesforo García a reprocharle amigablemente su desidia en mantener las relaciones entabladas con los políticos e intelectuales mexicanos afines a la causa hispanista:

Ha tenido Vd. un poco olvidados a sus amigos de México. A Justo, a Macedo, a García el del Museo, etc... Al mismo Presidente probablemente le hubiese agradado que le hubiese Vd. dado alguna noticia de sus conversaciones con el Rey en lo que se relaciona con la compenetración recíproca y amorosa del alma española con el alma latino-americana. Todo esto es necesario para que no sufra interrupción y mantenga apoyos decididos la alta política española que $\mathrm{Vd}$. y yo perseguimos. No lo descuide. ${ }^{64}$

61 Carta de José Porrúa a Rafael Altamira, México, 5 de febrero de 1910, IESJJA/LA, C-4/94.

62 Carta de Telesforo García a Rafael Altamira, México, 21 de febrero de 1910, IESJJA/LA, C-4/142.

63 Carta de Telesforo García a Rafael Altamira, México, 17 de junio de 1911, IESJJA/LA, C7/36. El caudillo conservador Rodríguez de San Pedro fue ministro de Instrucción Pública del gobierno de Maura que, a petición del rector Canella, otorgaría la excedencia de Altamira en 1909 para realizar su viaje americanista.

64 Carta de Telesforo García a Rafael Altamira, México, 22 de junio de 1910, IESJJA/LA, C6/34. García insistió con estos pedidos en otra carta, logrando que Altamira estableciera correspondencia con Justo Sierra (IESJJA/LA, C-6/154, Carta de Justo Sierra a Rafael Altamira, México, 7 de noviembre de 1910). 
En esos meses, García y otros notables de la comunidad insistieron acerca de la oportunidad de utilizar las condecoraciones reales para premiar e incentivar el compromiso de los principales líderes comunitarios, a la vez que señalaban la necesidad de servirse de ellas como instrumentos de atracción y confraternidad respecto de las élites mexicanas. La comunidad española era consciente de su influencia y poder económico, pero también de su mala imagen en la opinión pública y de las ambigüedades respecto del legado hispano en el imaginario popular. ${ }^{65}$ De allí que los líderes más perspicaces propusieran continuamente utilizar estos recursos simbólicos para halagar a los hispanófilos mexicanos y seducir a los políticos, predisponiéndolos en favor de los intereses comunitarios.

Los presidentes del Círculo Español Mercantil y de la Sociedad Española de Beneficencia sugirieron al vicecónsul de España en México, Federico Gutiérrez y Pico, que el gobierno hispano condecorara al gobernador de Veracruz, Teodoro Dehesa Méndez, antes de las celebraciones independentistas, como una forma «de alejar la posibilidad de que durante ellas haya alguna nota mortificante para nuestra patria». Ambos dirigentes recordaban el trabajo y el tiempo que había sido invertido para consolidar la situación de la colectividad española en México y la conveniencia de condecorar al gobernador, lo cual «además de ser una merecida recompensa sería también una medida política altamente beneficiosa para todos los intereses españoles que en esta jurisdicción radican». ${ }^{66}$

Telesforo García también defendía una política generosa en el otorgamiento de cruces y collares a los líderes de la emigración más comprometidos con la causa hispanista ${ }^{67}$ y a los políticos porfiristas más notorios. Pero García ya tenía muchos reproches que hacer a los políticos españoles por su comportamiento con el gobierno de México y por su sordera hacia los reclamos de los emigrados. Particular importancia tuvo, en aquellos momentos, la controversia entre la colonia española y el gobierno liberal a propósito de la representación peninsular en las fiestas del centenario mexicano, de la que García mantuvo prolijamente informado a Altamira. ${ }^{68}$

65 Pérez Vejo, 2010.

66 Duplicado de carta de Antonio del Fresno, Círculo Español Mercantil, y Leopoldo Palazuelos, Sociedad Española de Beneficencia, a Federico Gutiérrez y Pico, vice-cónsul de España, México, 23 de febrero de 1910, IESJJA/LA, C-22/104.

67 «No eche en saco roto lo que hablamos sobre cruces a esta gente. Respecto de los nuestros necesito una Gran Cruz de Isabel la Católica para Pepe [José] Sánchez Ramos; una encomienda de la misma Orden para Gonzalo de Murga, y una cruz ordinaria de Carlos III para José Vizoso» (Carta de Telesforo García a Rafael Altamira, México, 21 de febrero de 1910, IESJJA/LA, C-4/142).

68 Carta de Telesforo García a Rafael Altamira, México, 22 de junio de 1910, IESJJA/LA, C-6/34. 
El centenario, como efeméride fundacional, originó un gran interés político en el porfiriato, que constituyó en 1907, bajo el influjo de Justo Sierra, una Comisión Nacional del Centenario de la Independencia, encargada de organizar los fastos a escala nacional. ${ }^{69} \mathrm{El}$ envío de una delegación extraordinaria española, presidida por el capitán general Camilo García de Polavieja, preocupó a los emigrantes por su perfil conservador y ultracatólico y porque la jerarquía de la delegación era claramente inferior a la enviada en mayo de 1910 a la Argentina, presidida por Isabel de Borbón. Así pues, los dirigentes comunitarios solicitaron por telegrama la inclusión de «personal prestigioso civil y brillante militar» para «borrar desencanto, contrarrestar fría impresión y patriótico descontento» que se habían suscitado, a la vez que recomendaban enfáticamente que se reconociera con la orden del Toisón al presidente mexicano, «demasiado justificado por trascendentales servicios del Presidente a España y [a la] Colonia además [de] eminentes prestigios propios, causando pésimo efecto no concederlo ahora por haberse indicado varias veces». ${ }^{70}$

García apoyó estos reclamos con una carta personal para Canalejas en la que exponía el grave error que cometía el Gobierno enviando como cabeza de la delegación hispana a una «vieja reaccionaria», sin incluir al menos «dos o tres hombres importantes de reconocida significación democrática y de carácter civil», lo cual, preveía, tendría un «excelente efecto por las pretensiones republicanas que aquí arraigan». ${ }^{71}$ Otra de las quejas de García a Canalejas se refería a la condecoración insuficiente, a su juicio, que se le enviaba al presidente mexicano - el Collar de la Real Orden de Carlos III-, protestando por la reticencia a la hora de otorgar a Porfirio Díaz el Toisón y no reservar un par más para los presidentes de Argentina y Chile. ${ }^{72}$

El presidente Canalejas recibió también una carta de la colonia española en la que aseguraba que la «limitada» delegación del Estado sería lealmente recibida, a la vez que se presentaba otra queja amarga por lo mezquino del «galardón ofrecido al patriarca que, con admiración universal, rige los destinos de México» y por el silencio del Consejo de Ministros frente a las peticiones patrióticas de una colonia que siempre había sido leal con los gobiernos españoles, cualquiera fuera su signo político, y nunca

69 Guedea, 2012.

70 Copia de telegrama de las autoridades de la colonia española al presidente del Consejo de Ministros de España, México, 4 de agosto de 1910, IESJJA/LA, C-22/109.

71 Copia de la carta de Telesforo García a José Canalejas, 4 de agosto de 1910, IESJJA/LA, C$22 / 110$.

72 Idem. 
había desertado de auxiliar a España «cuando la fatalidad ó el dolor han tocado a sus puertas». ${ }^{73}$

A propósito de este silencio -ilustrativo de «cómo ayudan los Gobiernos españoles a las generosas iniciativas de sus colonias americanas»—, García confiaba a Altamira su escepticismo respecto de su «amigo» Canalejas, convencido de que nada de lo que se le dijera lograría atraer su atención, centrada por entonces en la «cuestión clerical» y en su propia «posición personal... vanidades y hasta odios». ${ }^{74}$ Persuadido de la ceguera de los políticos españoles, pronosticaba que la solicitud de condecoraciones, incluso las de menor rango, sería desatendida: «las cruces, pues, que nada cuestan y que bien y oportunamente repartidas constituirían un buen auxiliar de nuestros propósitos fraternales, quedarán relegadas al olvido, o vendrán cuando no hagan falta». ${ }^{75}$ Las consideraciones de García resultarían premonitorias, ya que a su muerte, en 1918, dichas condecoraciones seguían pendientes de consideración. ${ }^{76}$

Era evidente que los españoles de México tenían razones para estar preocupados por las políticas de sus gobiernos y esperaban utilizar sus vínculos con Altamira como una baza para producir un giro en las relaciones hispano-mexicanas. Pero poco pudo hacer Altamira para apoyar a Cólogan o a García cuando, tras su gratificante y prometedora recepción por parte de la Corona y el Gobierno, los mismos caudillos liberales - Moret, Romanones, Canalejas y García Prieto- que abrían espacios de colaboración institucional con los krausoinstitucionistas y que, en lo inmediato, lo promoverían a la Dirección de Primera Enseñanza, se apresuraban a expropiar en favor del Estado las posibles esferas de la acción americanista. ${ }^{77}$ En el marco de esta política, se liquidarían las aspiraciones del claustro de Oviedo de que se gestionara el intercambio intelectual con América desde el ámbito de la autonomía universitaria ${ }^{78}$ y se bloquearía la iniciativa de

73 Copia de carta de la colonia española en México a José Canalejas, México, 26 de agosto de 1910, IESJJA/LA, C-22/111. C-6/102.

74 Carta de Telesforo García a Rafael Altamira, México, 29 de agosto de 1910, IESJJA/LA,

75 Idem.

76 Altamira, 1917, 126.

77 Notas de Rafael Altamira para servir de guía de reclamos y preguntas al ministro de Instrucción Pública acerca de los proyectos derivados de la entrevista con el rey y sobre «Cuestiones referentes a la Inspección», s/l y s/f (redactadas entre septiembre y octubre de 1910), Instituto Juan Gil Albert, Fondo Altamira, II.FA.187. Los documentos del Fondo Altamira del Instituto Juan Gil Albert se encuentran hoy en el Archivo de la Fundación Residencia de Estudiantes de Madrid, Fondo Altamira.

78 Prado, 2007. 
reorganizar unitaria y transversalmente el aparato administrativo encargado de gestionar la política española hacia Hispanoamérica. ${ }^{79}$

Entre 1910 y 1911, luego de que lograra inscribir la cuestión hispanoamericana en la agenda del poder - al coste de que fuera absorbida y esterilizada por las instituciones estatales- y de que sus proyectos se estrellaran con la indiferencia política o administrativa, Altamira consideraría que la suerte del programa americanista y de la jerarquización de la imagen de España en América dependería de las acciones que pudieran desplegar, desde España, las instituciones americanistas y, desde América, las comunidades de emigrantes. ${ }^{80}$

En lo que respecta a las primeras, debe consignarse que su capacidad de acción y presión quedaría mermada en lo inmediato por la intervención de los gobiernos españoles, más atentos a neutralizar cualquier injerencia de la sociedad civil en la política exterior, que a implementar un auténtico giro americanista. De allí que los grandes caudillos conservadores y liberales, al tiempo que abrazaban una nueva retórica americanista, procuraran encauzar la imprevisible efervescencia panhispanista y boicotearan - a través de la Unión Ibero Americana de Madrid - el proyecto de federar las diferentes asociaciones americanistas, partenaires ideales de las asociaciones españolas de emigrantes en la potenciación del panhispanismo. ${ }^{81}$

En lo que respecta a las segundas, el problema de fondo radicaba - tanto para García como para Altamira - en que las comunidades de emigrantes eran sistemáticamente ignoradas en Madrid. El camino a transitar sería, pues, el que impulsaba García desde México: no esperar nada de la Restauración, auxiliar materialmente a España, promover unilateralmente las relaciones hispano-americanas, realizar su propia labor de propaganda hispanista y abocarse a fortalecer internamente las comunidades emigrantes, promoviendo la concentración patriótica y evitando tanto las tentaciones de republicanizar la colectividad, como las de forzar - desde dentro o desde la Península - una identificación con la España conservadora. ${ }^{82}$

La evolución de las relaciones entre España y las naciones americanas, ciertamente positiva en el mediano plazo, tuvo que sufrir en lo inmediato toda suerte de estancamientos y extravíos desmoralizantes para los

79 Altamira, 1911, 591-593. Carta de Manuel García Prieto a Rafael Altamira, San Sebastián, 3 de septiembre de 1910, IESJJA/LAC-6/104.

80 Altamira, 1917, 35 .

81 Dalla-Corte y Prado, 2005.

82 Copia de la carta de Telesforo García a José Canalejas, México, 4 de agosto de 1910, IESJJA/LA, C-22/110. 
impacientes americanistas españoles. Pero estas frustraciones no solo fueron causadas por las torpezas diplomáticas, sino también por vicisitudes americanas. Un caso notorio, quizás el más dramático, en el que las expectativas de avances inmediatos abiertas por el viaje de Altamira se vieron rápidamente frustradas fue precisamente el de México. En efecto, las convulsiones internas causadas por la sucesiva instalación de escenarios sediciosos, represivos, insurreccionales y revolucionarios tras la proclama del Plan de San Luis Potosí, implicaron el eclipse político de varios de los liberales más aperturistas y reformistas del porfiriato.

Este fue el caso de Justo Sierra, que renunciaría a su secretaría meses antes de la caída de Díaz, para consternación de su amigo Telesforo García, que prometía a Altamira observar cómo podía influir en su favor, de allí en adelante, en el Gobierno mexicano. ${ }^{83}$ García mantuvo a Altamira informado de las desventuras de Sierra ${ }^{84}$ antes de que el presidente Francisco I. Madero lo rehabilitara nombrándolo ministro plenipotenciario de México en España, en el que sería su último servicio público, ya que fallecería en Madrid el 13 de septiembre de 1912, al poco de hacerse cargo de la legación.

García informó a Altamira de la evolución del proceso revolucionario, testimoniando lo inesperado de las primeras convulsiones y minimizando inicialmente las consecuencias que podían derivarse aquella «revuelta», que inquietaba al Gobierno aunque «sin amenazarlo seriamente», y le explicaba que a su juicio lo que hacía grave la situación era que Estados Unidos alimentaba la sedición por sus intereses respecto de la Baja California. En todo caso, García concluía recomendando a Altamira, interesado en hacer escala en México al planificar su futuro viaje a los Estados Unidos, que «no tome resolución alguna sin que el horizontes se despeje por completo»..$^{85}$

Meses después, García reafirmaba su desconcierto, pero no solo exhibía un previsible tono crítico hacia Madero, sino un punto de vista muy diferente del sentido que tomaban los acontecimientos:

bástele por ahora saber que todo el antiguo régimen de orden y progreso se encuentra profundamente trastornado. Había ciertamente en el estado político anterior graves vicios que corregir de orden mental y de orden práctico; pero la mutación teatral que hemos sufrido no parece llamada a corregirlos, porque las revoluciones suelen aprovecharse cuando traen hombres de valer consigo y cuando cuentan con una masa

83 Carta de Telesforo García a Rafael Altamira, México, 29 de marzo de 1911, IESJJA/LA, C-7/18. 84 Carta de Telesforo García a Rafael Altamira, México, 17 de junio de 1911, IESJJA/LA, C-7/36. 85 Carta de Telesforo García a Rafael Altamira, México, 29 de marzo de 1911, IESJJA/LA, C-7/18. 
capaz de comprender y de servir un ideal elevado. La revolución nada de esto arrastra tras de sí. Es simplemente la repetición de esa borrachera de ofrecimientos verbales que tan fecundos veneros ha tenido siempre en los países americanos de nuestro origen, que ni escarmientan con sus eternos fracasos, ni se enmiendan con sus invariables decepciones. No sabría qué decir si se me preguntara cuál ha sido la causa material e inmediata de un cambio tan inesperado y tan brusco. ${ }^{86}$

Describiendo la debacle del porfiriato poco después de alcanzada su aparente apoteosis en 1910, García retrataba la traumática salida de la escena política de una generación política «positivista», en beneficio de un grupo imprevisible de advenedizos:

Invadió los ánimos una especie de fiebre que en pocas semanas recorrió todo el país, produciendo un atolondramiento completo en la vieja administración absolutista [...] El fenómeno psicológico ha sido, pues, de cansancio, de aburrimiento, de deseo insaciable de cambiar, sin que el odio, ni la ira, ni la venganza tuviera más que tal cual manifestación esporádica hija de la barbarie o de alguna que otra mala pasión individual. Lo viejo se fue, llevándose consigo mucha honradez, mucho prestigio, mucho talento y también una gran cantidad de errores, abusos y corruptelas propias de toda administración no discutida, que considera como una propiedad suya el ejercicio de las funciones públicas. ${ }^{87}$

El naufragio de una generación política más conservadora que liberal haría zozobrar también los proyectos de asociación hispano-mexicanos, bosquejados en torno al panhispanismo promocionado por Altamira.

\section{Reflexiones finales}

El análisis de la escala mexicana de Rafael Altamira permite reconocer una serie de elementos recurrentes en el viaje americanista que es necesario identificar.

Tenemos el contexto de unas relaciones bilaterales normalizadas en un ambiente diplomático favorable para el acercamiento, de unos regímenes políticos propios del capitalismo oligárquico con dinámicas y problemáticas equivalentes, y de unos climas ideológicos convergentes instalados tras la guerra hispano-norteamericana de 1898 que facilitaron el diálogo entre americanistas e hispanófilos

86 Carta de Telesforo García a Rafael Altamira, México, 17de junio de 1911, IESJJA/LA, C-7/36.

87 Idem. 
Ante esta configuración, concurre la acción de una institución pública autónoma española con marcada sensibilidad americanista que organiza una embajada intelectual independiente del Gobierno, y un embajador intelectual de reconocido prestigio académico, capaz de articular desde presupuestos patrióticos y apartidarios, un discurso panhispanista y unas estrategias sociales eficaces de confraternización.

Esta acción es apoyada, en el terreno, por las élites de un asociacionismo español interesado en fortalecer y cohesionar a su colectividad, prestigiando la imagen de España y utilizando sus redes sociales para promocionar dicha embajada intelectual ante sus interlocutores de las élites gobernantes, y por una legación diplomática dispuesta a secundar esa iniciativa y extraer de ellas líneas de acción diplomática para el futuro.

Esta embajada, así planteada, gestionada y apoyada, será recibida por un campo cultural en desarrollo, con unas instituciones universitarias, académicas y culturales en construcción, abiertas a incorporar aportes de los intelectuales españoles en el área pedagógica, jurídica, historiográfica y científica; por un campo de poder local interesado en utilizar las ciencias sociales y las humanidades para fortalecer el proceso de institucionalización estatal; y por unos referentes políticos e ideológicos locales interesados en incorporar críticamente el legado hispano dentro de un proyecto propio y de actuar como valedores locales del embajador intelectual.

Estos contextos, acciones y recepciones nos muestran la omnipresencia palpable de unas redes sociales cuyas tramas superpuestas - de matriz nacional, regional, iberoamericana y europeas - involucraban a casi todos los actores que participaron de una forma u otra de la misión del embajador intelectual,$^{88}$ en una coyuntura propicia marcada por el ciclo de efemérides de los centenarios de las independencias.

La presencia y actuación de estos factores en la etapa mexicana del viaje de Altamira - una de las tres principales del proyecto ovetense- nos dan la pauta de que poseemos elementos para relacionar esta experiencia con la argentina y cubana, pero también con la peruana y chilena, que muestran, todas ellas, patrones similares. En todo caso, estando todavía en el proceso de reconstruir los hechos, redes y actores en base a la documentación española y de cada uno de los países involucrados, podemos proponer que para avanzar en el conocimiento de estas y otras iniciativas similares es

88 Los avances en la formalización de las redes sociales operantes tras la misión de Altamira en México confirman, de momento, nuestros planteamientos iniciales (Prado, 2005, 29-53 y 461-491; y 2008 b) y la viabilidad del tipo ideal propuesto, en lo que a estos asuntos atañe: Ledezma, 2013, 437-447. 
necesario relacionar estos elementos para construir, en lo inmediato, un tipo ideal de embajada intelectual americanista.

Pero también es necesario registrar que, más allá de las recurrencias, la escala mexicana de Altamira muestra también especificidades que deben tenerse en cuenta: a) la migración masiva no formaba parte de los condicionantes estructurales que posibilitaban el acercamiento, al igual que en Perú y Chile y a diferencia de Argentina, Uruguay y Cuba; b) el asociacionismo español con ser denso e influyente, era pequeño, sumamente elitista y altamente fragmentado por conflictos facciosos; c) la necesidad de apoyarse en los principales líderes étnicos en el marco de una colectividad dividida, generó tensiones intracomunitarias, a diferencia de lo ocurrido en los demás países visitados; d) el panhispanismo fue bien recibido porque encajaba en los intereses de las élites locales, pero no en el marco de proyectos liberal-reformistas en el ámbito político-social —como en Argentina y Uruguay-, sino de otros más ortodoxos en que el legado hispano era asumido como un instrumento de legitimación cultural de una hegemonía política y social oligárquica y excluyente ${ }^{89}$ e) el compromiso mostrado por la legación española fue muy superior al de otras, siendo solo comparable con lo ocurrido en Uruguay.

Ponderando estas especificidades mexicanas, podemos ver que representan, en principio y en la mayoría de los casos, diferencias de matices o grados en la manifestación de los factores antes mencionados y presentes en otras escalas del viaje de Altamira ya estudiadas por la historiografía. Creemos que esto es prometedor en lo que hace a las potencialidades analíticas del tipo ideal de embajada intelectual, en tanto estas parecen no constituir singularidades no integrables en el modelo. En este sentido, la flexibilidad de este instrumento analítico estaría en condiciones de captar los elementos esenciales de la exitosa misión de Altamira en América - y el caso mexicano parece confirmarlo-, lo cual nos permitiría superar el anecdotario y los enfoques centrados en la exaltación del carisma de su protagonista.

Observando la evidencia a través de tal modelo puede apreciarse mejor que desde la crónica de viajes la conformación —en un contexto propicio en el que convergen factores estructurales y coyunturales- de una alianza estratégica que no solo se recreaba en ideales patrióticos y altruistas, sino que expresaba la articulación pragmática de los intereses

89 Guedea, 2012. 
que representaban, en primer lugar, los embajadores intelectuales españoles, centrados en impulsar un giro político panhispanista, en fortalecer el movimiento americanista refrendando sus propios liderazgos y en trabar fuertes compromisos con las élites locales; en segundo lugar, los dirigentes del mundo asociativo emigrante, enfocados a prestigiar la colectividad, recrear el vínculo identitario y fortalecer su liderazgo potenciando su capacidad de interlocución con los poderes locales; en tercer lugar, los diplomáticos, interesados en promover la buena imagen de España y obtener avances reconocibles en unas siempre espinosas relaciones bilaterales, como modo de aumentar su propio prestigio profesional; y en cuarto lugar, los sectores revisionistas e hispanófilos de las élites intelectuales americanas interesadas en integrar la otrora despreciada tradición cultural hispana, dentro de diferentes proyectos de construcción nacional.

Por esto proponemos que el tipo ideal de embajada intelectual americanista puede servir para comprender las pautas dentro de las cuales se desenvolvieron otros embajadores intelectuales españoles durante las dos primeras décadas del siglo XX y parte de la tercera, y también para comprender la viabilidad de las intervenciones paradiplomáticas, hegemónicas en esta etapa, ante las renuncias o incapacidades de los estados iberoamericanos.

Volviendo al caso mexicano para terminar, es indudable que la $\mathrm{emba}$ jada intelectual de Rafael Altamira en el centenario daría tardíos frutos en lo que hace al desarrollo de las relaciones intelectuales hispano-mexicanas. El camino sería lo suficientemente largo como para que otros actores de este fenómeno, como Bernardo de Cólogan, Telesforo García, Justo Sierra o Fermín Canella no llegaran a verlos y para que Altamira apenas pudiera apreciar alguno de ellos antes de morir en México en 1951, tras contribuir a reconstruir allí la tradición académica del americanismo español..$^{90}$ Este americanismo recreado en el exilio no hablaba, ciertamente, en nombre de la España que proponía a América una hispanidad reaccionaria, sino por cuenta de una fantasmal República española atrapada en el amargo exilio mexicano - en buena medida una república de las letras-, apartada ya, por imposición de la realidad, de la utopía panhispanista.

Recibido el 16 de enero de 2015 Segunda versión: 2 de julio de 2015 Aceptado el 11 de septiembre de 2015

90 Sánchez Cuervo, 2005, 231-246. 


\section{Referencias bibliográficas}

Aken, Mark J. van, Pan-hispanism: its origin and development to 1866, Millwood, NY, Kraus Reprint, 1980 [1959].

Altamira, Rafael, Discurso leído en la solemne apertura del curso académico de 1898 a 1899 por el Doctor D. Rafael Altamira y Crevea, catedrático numerario de Historia del Derecho, Oviedo, Adolfo Brid, 1898.

- Mi viaje a América. Libro de documentos, Madrid, Victoriano Suárez, 1911.

- España y el programa americanista, Madrid, América, 1917.

- La formación del jurista, edición de Jaime del Arenal Fenochio, México, Escuela Libre de Derecho, 1993.

Asín Vergara, Rafael et al., Rafael Altamira 1866-1951, Instituto de Estudios Juan Gil-Albert, Alicante, 1987.

Bernabéu Albert, Salvador, 1892: El IV Centenario del Descubrimiento de América en España: coyuntura y conmemoraciones, Sevilla, CSIC, 1987.

Cagiao Vila, Pilar y Rey Tristán, Eduardo (coords.), Aproximaciones al americanismo entre 1898 y 1936: Proyectos, Instituciones y Fondos de Investigación, Santiago de Compostela, USC, 2006.

Cerutti, Mario, Empresarios españoles y sociedad capitalista en México (18401920), Colombres, Fundación Archivo de Indianos, 1995.

Dalla-Corte, Gabriela y Prado, Gustavo H., «El movimiento americanista español en la coyuntura del Centenario. Del impulso ovetense a la disputa por la hegemonía entre Madrid y Cataluña», Estudios Migratorios Latinoamericanos, 56, Buenos Aires, 2005, 31-64.

Domínguez Martín, Rafael y Cerutti, Mario (eds.), De la colonia a la globalización. Empresarios cántabros en México, Santander, Universidad de Cantabria, 2006.

García-Montón García-Baquero, Isabel, «El Congreso Social y Económico Hispanoamericano de 1900: un instrumento del hispanoamericanismo modernizador», Revista Complutense de Historia de América, 25, 1999, 281-294.

Guedea, Virginia, «El primer centenario en México», en Moreno Luzón, Javier y Gutiérrez Viñuales, Rodrigo (eds.), Memorias de la independencia: España, Argentina y México en el primer centenario (1908-1910-1912), Madrid, Sociedad Estatal para la Acción Cultural, 2012, 45-59.

Ledezma, Juan Manuel, «Rafael Altamira en México: actividades con la colonia española», en Ferrandiz Lozano, José y La Parra López, Emilio (dirs.), Rafael Altamira: idea y acción hispanoamericana, Alicante, Instituto Juan Gil Albert, 2011, 97-118.

- «Telesforo García: un emigrante montañés en el Porfiriato», Actas del Congreso Internacional América Latina: La autonomía de una región. XV Encuentro de Latinoamericanistas Españoles, Madrid, Trama Editorial, CEEIB, 2012, 990-1000. 
- «Los programas hispanoamericanistas de Rafael Altamira y su primera estancia en México, 1909-1910: hacia la conformación de una red intelectual», tesis doctoral inédita, Madrid, Universidad Autónoma de Madrid, 2013.

Lida, Clara E. (ed.), Una inmigración privilegiada: comerciantes, empresarios y profesionales españoles en México en los siglos XIX y XX, Madrid, Alianza, 1994.

Mac Gregor, Josefina, México y España: del porfiriato a la Revolución, México DF, Instituto Nacional de Estudios de la Revolución Mexicana, 1992.

- «México y España: de la representación diplomática oficial a los agentes confidenciales, 1910-1915», Historia Mexicana, L, 2, México, 2000, 309-330.

Marcilhacy, David, Raza hispana. Hispanoamericanismo e imaginario nacional en la España de la Restauración, Madrid, CEPC, 2010.

Melón Fernández, Santiago, El viaje a América del profesor Altamira, Oviedo, Universidad de Oviedo, 1987.

Niño, Antonio, «Hispanoamericanismo, regeneración y defensa del prestigio nacional (1898-1931)», en Pérez Herrero, Pedro y Tabanera, Nuria (coords.), España/América Latina: un siglo de políticas culturales, Madrid, Síntesis, 1993, 15-48.

Núñez Seixas, Xosé M., «Liderazgo étnico en comunidades de emigrantes: algunas reflexiones», en Sánchez-Albornoz, Nicolás y Llordén Miñambres, Moisés (comps.), Migraciones iberoamericanas. Reflexiones sobre Economía, Política y Sociedad, Colombres, Fundación Archivo de Indianos, 2003, 347-388.

Pelosi, Hebe Carmen, Rafael Altamira y la Argentina, Alicante, Universidad de Alicante, 2005.

Pérez Vejo, Tomás, «La difícil herencia: hispanofobia e hispanofilia en el proceso de construcción nacional mexicano», en Suárez Cortina, Manuel y Pérez Vejo, Tomás (coords.), Los caminos de la ciudadanía. México y España en perspectiva comparada, Madrid, Biblioteca Nueva, 2010, 219-230.

- «Cuando los españoles estuvieron a punto de dejar de ser gachupines», en Pérez Vejo, Tomás (coord.), Enemigos íntimos: España, lo español y españoles en la configuración nacional hispanoamericana, 1810-1910, México DF, El Colegio de México, 2011, 213-244.

Prado, Gustavo H., «Rafael Altamira, el hispanoamericanismo liberal y la evolución de la historiografía argentina en el primer cuarto del siglo $\mathrm{XX} »$, tesis doctoral, Oviedo, Universidad de Oviedo, 2005.

- «La Universidad de Oviedo, Rafael Altamira y la JAE: controversias en torno a la gestión de las relaciones intelectuales hispano-americanas (19091911)», Revista de Indias, LXVII, 239, Madrid, 2007, 33-58.

- El Grupo de Oviedo en la historiografía y la controvertida memoria del krausoinstitucionismo asturiano, Oviedo, KRK, 2008a. 


\section{AMERICANISTAS, DIPLOMÁTICOS Y LÍDERES DE LA EMIGRACIÓN ESPAÑOLES}

- Rafael Altamira en América. Historia e historiografía del proyecto americanista de la Universidad de Oviedo (190-1910), Madrid, CSIC, 2008b.

Rama, Carlos M., Historia de las relaciones culturales entre España y la América Latina. Siglo XIX, Madrid, FCE, 1982.

Sánchez Cuervo, Antolín, «México y la tradición del krausismo: del liberalismo de la Reforma al exilio institucionista», en Álvarez Lázaro, Pedro F. y VázquezRomero, José Manuel (eds.), Krause, Giner y la Institución Libre de Enseñanza. Nuevos estudios, Universidad de Comillas, 2005, 207-243.

Sepúlveda Muñoz, Isidro, El sueño de la Madre Patria, Madrid, Marcial Pons, 2005.

Suárez Cortina, Manuel (ed.), México y España. Historia y memoria de dos siglos (1810-2010), Madrid, Universidad de Cantabria y Editorial Síntesis, 2013.

Valero Juan, Eva María, Rafael Altamira y la reconquista espiritual de América, Alicante, Universidad de Alicante, 2003. 